\title{
Quantifying the changes of soil surface microroughness due to rainfall impact on a smooth surface
}

\author{
Benjamin K. B. Abban $^{1}$, A. N. (Thanos) Papanicolaou ${ }^{1,5}$, Christos P. Giannopoulos ${ }^{1}$, Dimitrios C. Dermisis ${ }^{2}$, \\ Kenneth M. Wacha ${ }^{3}$, Christopher G. Wilson ${ }^{1}$, and Mohamed Elhakeem ${ }^{4}$ \\ ${ }^{1}$ Hydraulics and Sedimentation Lab, Department of Civil \& Environmental Engineering, University of Tennessee - Knoxville, \\ Knoxville, TN 37996, USA \\ ${ }^{2}$ College of Engineering, Department of Chemical, Civil \& Mechanical Engineering, McNeese State University, \\ Lake Charles, LA 70605, USA \\ ${ }^{3}$ USDA-ARS - National Laboratory for Agriculture and the Environment, Ames, IA 50011, USA \\ ${ }^{4}$ Abu Dhabi University, Abu Dhabi, P.O. Box 59911, Abu Dhabi, United Arab Emirates \\ ${ }^{5}$ Tennessee Water Resources Center, Knoxville, TN 37996, USA
}

Correspondence to: Athanasios Thanos N. Papanicolaou (tpapanic@utk.edu)

Received: 3 December 2016 - Discussion started: 23 January 2017

Revised: 24 July 2017 - Accepted: 29 August 2017 - Published: 28 September 2017

\begin{abstract}
This study examines the rainfall-induced change in soil microroughness of a bare smooth soil surface in an agricultural field. The majority of soil microroughness studies have focused on surface roughness on the order of $\sim 5-$ $50 \mathrm{~mm}$ and have reported a decay of soil surface roughness with rainfall. However, there is quantitative evidence from a few studies suggesting that surfaces with microroughness less than $5 \mathrm{~mm}$ may undergo an increase in roughness when subject to rainfall action. The focus herein is on initial microroughness length scales on the order of $2 \mathrm{~mm}$, a low roughness condition observed seasonally in some landscapes under bare conditions and chosen to systematically examine the increasing roughness phenomenon. Three rainfall intensities of 30,60 , and $75 \mathrm{~mm} \mathrm{~h}^{-1}$ are applied to a smoothened bed surface in a field plot via a rainfall simulator. Soil surface microroughness is recorded via a surface-profile laser scanner. Several indices are utilized to quantify the soil surface microroughness, namely the random roughness (RR) index, the crossover length, the variance scale from the MarkovGaussian model, and the limiting difference. Findings show a consistent increase in roughness under the action of rainfall, with an overall agreement between all indices in terms of trend and magnitude. Although this study is limited to a narrow range of rainfall and soil conditions, the results suggest that the outcome of the interaction between rainfall and a soil surface can be different for smooth and rough surfaces
\end{abstract}

and thus warrant the need for a better understanding of this interaction.

\section{Introduction}

Soil surface roughness influences many hydrologic processes such as flow partitioning between runoff and infiltration, flow unsteadiness, and soil mobilization and redeposition on scales ranging from a few millimeters to hillslope level (e.g., Huang and Bradford, 1990; Magunda et al., 1997; Zhang et al., 2014).

There are three distinct classes of microtopography surface roughness (Fig. 1a) for agricultural landscapes, each one of them depicting a representative length scale (Römkens and Wang, 1986; Potter, 1990). Following Oades and Waters (1991), the first class includes microrelief variations from individual soil grains to aggregates on the order of $0.053-2.0 \mathrm{~mm}$. The second class consists of variations due to soil clods ranging between 2 and $100 \mathrm{~mm}$. The third class of soil surface roughness is systematic elevation differences due to tillage, referred to as oriented roughness (OR), ranging between 100 and $300 \mathrm{~mm}$.

From those outlined above, the first two classes are the so-called random roughness (RR), and constitute the main focus of the present research. RR is quantified on a sur- 


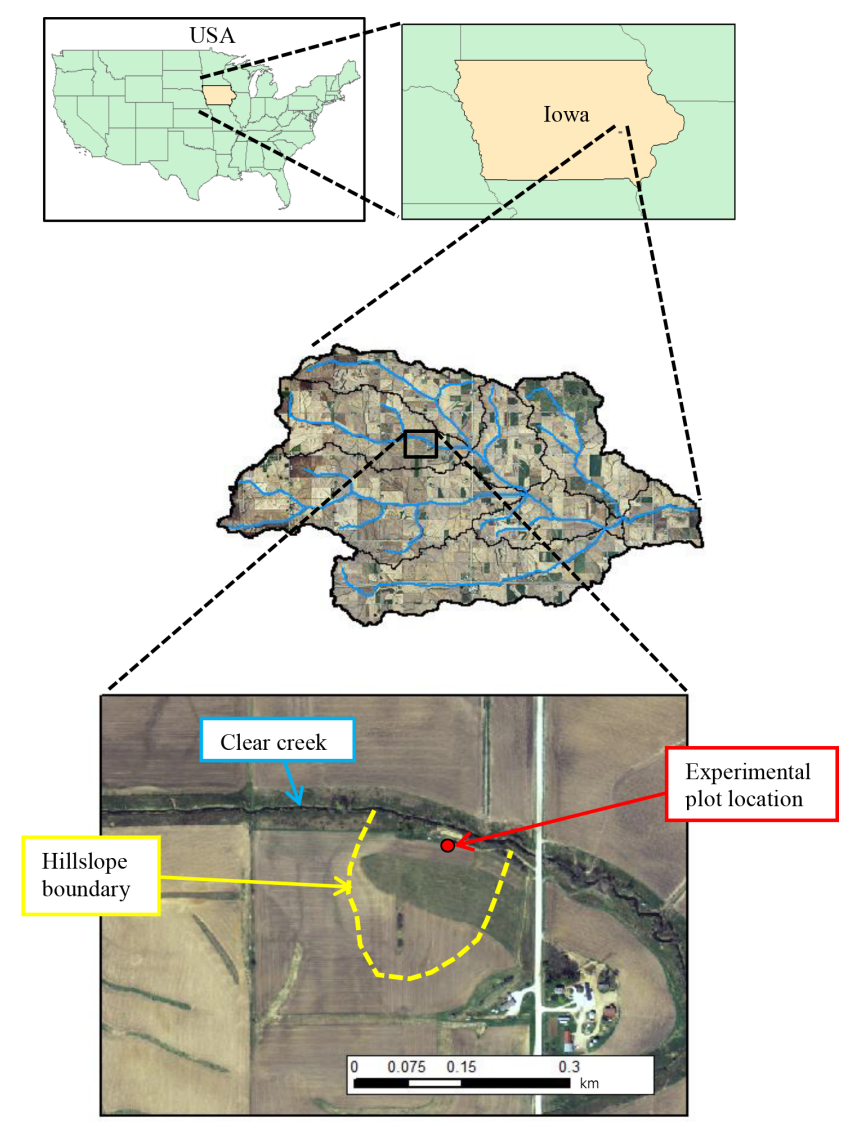

Figure 1. Location of experimental plot in the headwaters of Clear Creek, IA $\left(41.74^{\circ} \mathrm{N},-91.94^{\circ} \mathrm{W}\right)$.

face after correction for both slope and tillage marks. Contrary to OR, which changes seasonally and during crop rotations, RR changes on an event basis (Abaci and Papanicolaou, 2009). RR reflects the effects of rainfall action on the soil surface and inherently varies in space and time. As a result, RR affects key hydrologic processes at the soil scape and ultimately on the hillslope scale, e.g., infiltration, overland flow, etc. (Gómez and Nearing, 2005; Chi et al., 2012).

Several studies have been performed to characterize RR. Most have focused on initial microroughness length scales of 5-50 mm (e.g., Zobeck and Onstad, 1987; Gilley and Finkner, 1991). In these studies, a decay of roughness due to precipitation action is predicted, since rainfall impact and runoff "smoothen" the rough edges of soil grains, aggregates, and clods, especially in the absence of cover (Potter, 1990; Bertuzzi et al., 1990; Vázquez et al., 2008; Vermang et al., 2013). There are few studies that have examined surfaces with initial microroughness less than $5 \mathrm{~mm}$, a low roughness condition observed seasonally in some landscapes under bare conditions (e.g., Kamphorst et al., 2000; Vázquez et al., 2008; Zheng et al., 2014). Hereafter, for shortness, tests with initial RR less than $5 \mathrm{~mm}$ will be referred to as "smooth", whereas tests with initial RR greater than $5 \mathrm{~mm}$ will be re- ferred to as "rough". There are some quantitative indications that under bare smooth surface conditions, soil surface roughness may actually increase under the action of rainfall. Specifically, the study by Huang and Bradford (1992) calculated the semivariance with respect to length scale before and after rainfall, and an increase in roughness with rainfall was denoted using the Markov-Gaussian model for a surface with low initial roughness. Rosa et al. (2012) introduced an index (called the roughness index) estimated from the semivariogram to describe roughness, and an increase in the index with rainfall was observed under some conditions, and attributed to the fragmentation of aggregates and clods to smaller aggregates. Zheng et al. (2014) also reported an increase in values of the RR after the application of rainfall on smooth soil surfaces. However, none of the above studies acknowledged or related the increasing trend in surface microroughness to rainfall impact on smooth surfaces.

The main goal of this study is to examine changes in RR under rainfall impact for initial microroughness less than $2 \mathrm{~mm}$, since this appears to be the lower limit of roughness scales examined in the literature. It is postulated that an increase in microroughness may occur under the action of rainfall on preexisting smooth surfaces due to the nature of the interaction between rainfall and the soil surface. To meet the goal, we employ four commonly used indices: the RR index, the crossover length, the variance scale from the MarkovGaussian model, and the limiting difference. The last three indices are alternate methods and used here to supplement the RR index analysis for relative change in roughness.

\section{Materials and methods}

\subsection{Experimental conditions}

This study was conducted on an experimental plot of the US National Science Foundation Intensively Managed Landscapes Critical Zone Observatory in the headwaters of Clear Creek, IA $\left(41.74^{\circ} \mathrm{N},-91.94^{\circ} \mathrm{W}\right.$ and an elevation of 250 ma.s.l. - above mean sea level; Figs. 1 and 2). The soil series at the plot where the experiments were conducted is Tama (fine-silty, mixed, superactive, Mesic $\mathrm{Cu}-$ mulic Endoaquoll) (http://criticalzone.org/iml/infrastructure/ field-areas-iml/). It consists of $5 \%$ sand, $26 \%$ clay, $68 \%$ silt, and an organic matter content of $4.4 \%$. The aggregate size distribution of the soil consists of $19 \%$ of the soil size fraction less than $250 \mu \mathrm{m}, 48 \%$ between $250 \mu \mathrm{m}$ and $2 \mathrm{~mm}$, and $33 \%$ greater than $2 \mathrm{~mm}$. These soils contain both smectite and illite, with high cation exchange capacity between 15 and $30 \mathrm{cmol}_{\mathrm{c}} \mathrm{kg}^{-1}$ ). The experimental plot was uniform in terms of downslope curvature, its gradient was $9 \%$, and the plot size was approximately $7 \mathrm{~m}$ long by $1.2 \mathrm{~m}$ wide.

The soil surface was prepared before each experiment by tamping using a plywood board to create a smoothened surface. This was done to ensure a consistency in surface rough- 


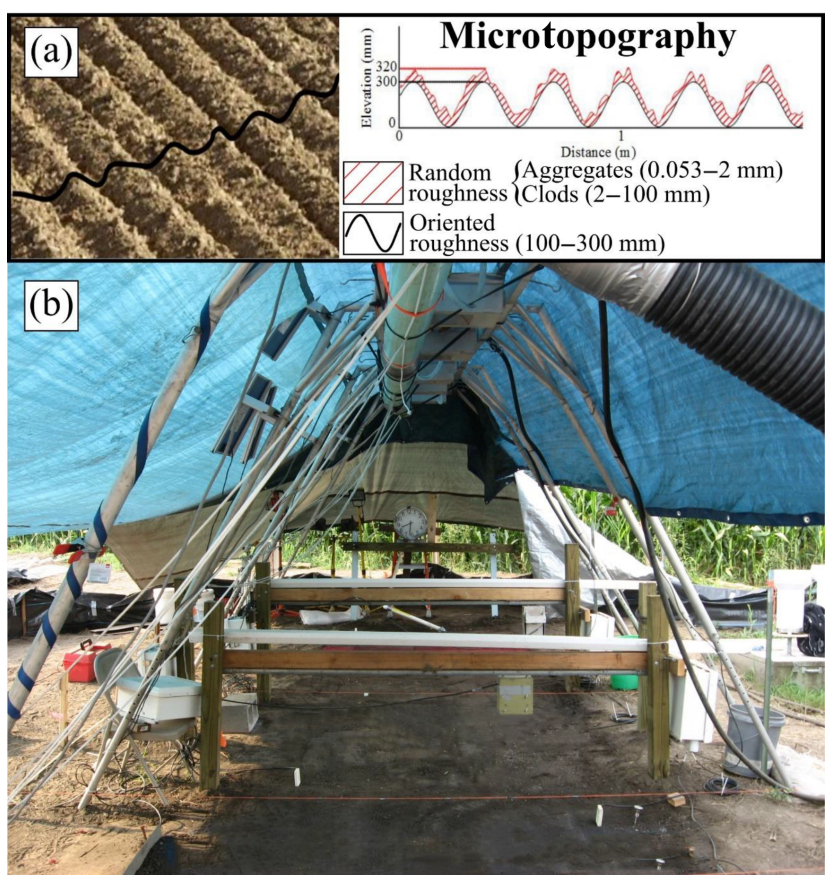

Figure 2. (a) Types of soil surface microroughness. (b) Experimental plot. The rainfall simulator is placed above the bare soil surface and a base made of wood is put into place to facilitate the movement of the surface-profile laser scanner.

ness between the experiments, as well as to ensure that any potential bias introduced in the plot preparation would be also be consistent, if not minimal. This was confirmed by the observed roughness of the experiment replicates. Rainfall was applied to the plot using Norton ladder multiple intensity rainfall simulators designed by the USDA-ARS National Soil Erosion Research Laboratory, IN. Figure 3 shows the setup for all the experimental runs considered in the present study. For each test, three rainfall simulators were mounted in series over the experimental plot (Fig. 3a) and approximately $2.5 \mathrm{~m}$ atop the plot surface (Fig. 3b) in order to ensure that raindrop terminal velocity was reached. Water was continuously pumped from a water tank under controlled pressure, and uniform rainfall was applied through oscillating VeeJet nozzles which provided spherical drops with median diameters between 2.25 and $2.75 \mathrm{~mm}$ and a terminal velocity between 6.8 and $7.7 \mathrm{~m} \mathrm{~s}^{-1}$ depending on the rainfall intensity. The distribution of raindrop sizes generated by the rainfall simulators was calibrated using a disdrometer and followed a Marshall-Palmer distribution (Elhakeem and Papanicolaou, 2009), which is a widely accepted distribution for natural raindrop sizes in the US Midwest, where the study was performed (Marshall and Palmer, 1948). The calibration of the raindrop sizes was achieved by adjusting the pressure and swing frequency of the VeeJet nozzles. This level of attention was taken to minimize any potential biases compared to natural rainfall with respect to raindrop size distribution,

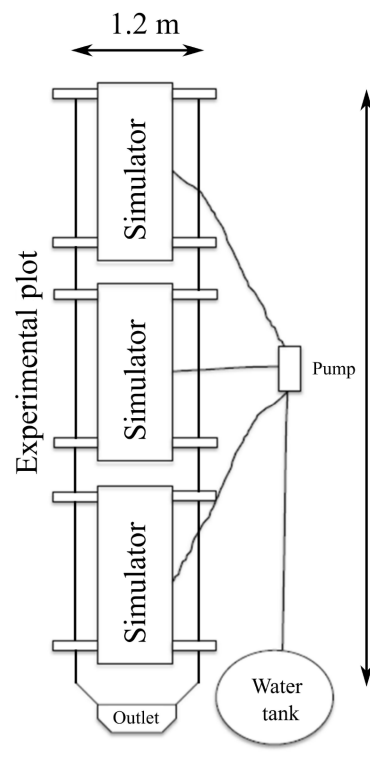

(a)

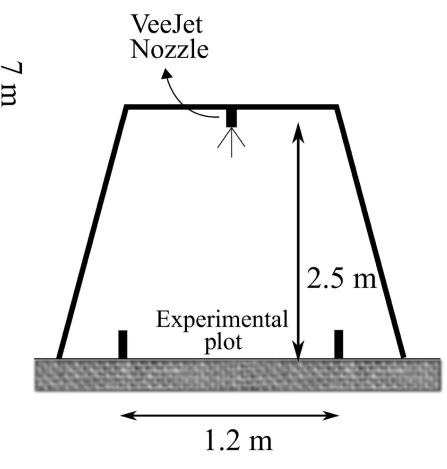

(b)
Figure 3. Setup of the experimental tests: (a) rainfall simulators are mounted in series and a pump provides them with water from a tank. (b) Rainfall simulators are placed and adjusted at a height of $2.5 \mathrm{~m}$ above the experimental plot surface to ensure drop terminal velocity is reached.

and, thus, render the rainfall simulation experiments scalable to other regions experiencing the same type of soil, bare surface, roughness conditions, and natural rainfall characteristics.

Surface elevations were obtained prior to and after the completion of the experiments via an instantaneous digital surface-profile laser scanner (Darboux and Huang, 2003), developed by the USDA-ARS National Soil Erosion Research Laboratory, IN (Fig. 4a). Laser scanner measurements before the runs confirmed that the overall microrelief was less than $2 \mathrm{~mm}$. Horizontal and vertical accuracies of the laser are $0.5 \mathrm{~mm}$. Thus, microroughness features less than $0.5 \mathrm{~mm}$ may not have been captured in the analysis. Points were measured every $1 \mathrm{~mm}$. The system consists of two laser diodes mounted $40 \mathrm{~cm}$ apart to project a laser plane over the targeted surface. The beam is captured by an 8 bit, high-resolution progressive scan charge-couple device camera with 1030 rows $\times 1300$ columns and a $9 \mathrm{~mm}$ lens. The camera and lasers are mounted on a $5 \mathrm{~m}$ long carriage assembly, and their movement on the carriage is controlled by software that regulates the travel distance based on a user-specified distance (Fig. 4a). Information captured by the camera is recorded with an attached computer. The information from each scan is converted into a set of $(x, y, z)$ coordinates using a calibration file and the software developed from the USDA-ARS National Soil Erosion Research Laboratory for data transformation as explained by Darboux and Huang (2003). The set of $(x, y, z)$ coordinates obtained for 

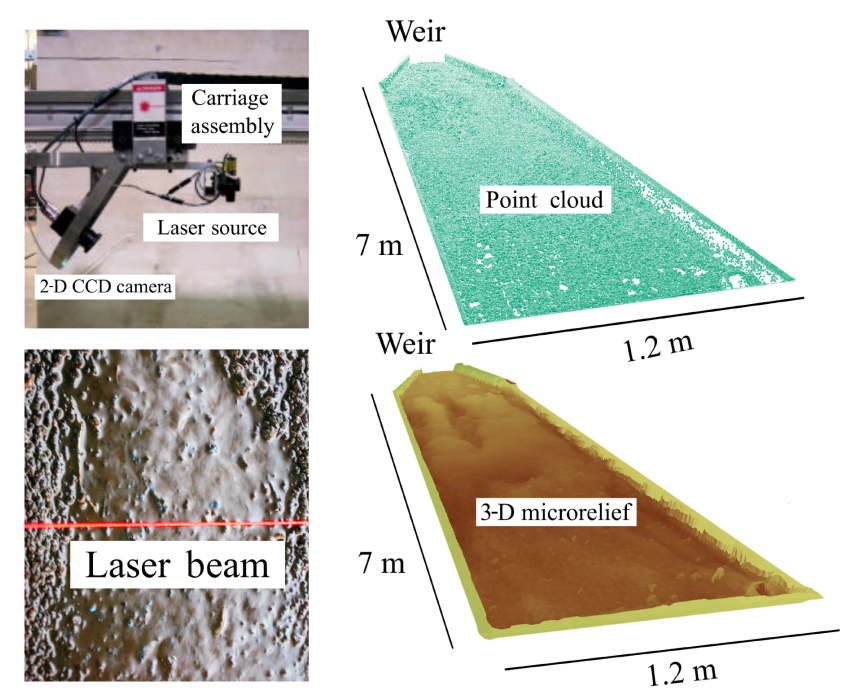

(a)

Figure 4. (a) Instantaneous digital surface-profile laser scanner used in the experimental runs and laser beam projected on the soil surface. (b) Cloud of $(x, y, z)$ data acquired from the laser scanner for an experimental test along with the associated 3-D representation of the soil surface microrelief through inverse distance weighted interpolation.

each experiment are imported into ArcGIS 10.3.1 in order to create the corresponding digital elevation models (DEMs) through inverse distance weighting interpolation and thereby visualize or analyze the surfaces (Fig. 4b). The resulting DEMs have a horizontal resolution of $1 \mathrm{~mm}$ and an accuracy of $0.5 \mathrm{~mm}$ in the vertical.

Three tests of varying rainfall intensity were conducted on the experimental plot. Rainfall intensities were 30, 60, and $75 \mathrm{~mm} \mathrm{~h}^{-1}$ for experiments $1-3$, respectively. These simulated intensities represent typical storms observed in the region of South Amana where the plot is located (Huff and Angel, 1992). Three replicates of each rainfall intensity case were performed until steady-state conditions were achieved, and repeatability was confirmed by evaluation of changes in $\mathrm{RR}$ at specific cross sections in the rain-splash-dominated zone. It was found that on average, the relative error of the RR ratios between replicates did not exceed $7 \%$. The volumetric water content was recorded via six 5TE soil moisture sensors manufactured by Decagon Devices, Inc. and placed along the plot to a depth of $10 \mathrm{~mm}$. The initial volumetric water content was found to be similar for each experiment and approximately equal to $35 \%$ at the whole plot, where the field capacity of the specific soil is $38 \%$. Each experiment was run for nearly $5 \mathrm{~h}$, sufficiently long to reach steadystate conditions, as confirmed by weir readings and discrete samples taken at the outlet of the plot. The infiltration rate was estimated during all rainfall simulation runs by subtracting the measured runoff rates from the constant rainfall rates.

This approach has been commonly used in plot experiments and provides a good estimate of the spatially averaged infiltration rates (e.g., Mohamoud et al., 1990; Wainwright et al., 2000). Averaged saturated hydraulic conductivity values ranged from 3.20 to $4.56 \mathrm{~mm} \mathrm{~h}^{-1}$, which are in agreement with the averaged saturated hydraulic conductivity value of $4.3 \mathrm{~mm} \mathrm{~h}^{-1}$ measured by Papanicolaou et al. (2015a) using semiautomated double-ring infiltrometers at the field where the study was performed. Although the average saturated hydraulic conductivity values were low with respect to the applied rainfall rates, minimal ponding was observed on the experimental plot, owing to the smooth bare conditions and the high plot gradient of $9 \%$, which led to low depressional storage.

The initial microroughness length scale in Experiment 1 $(1.17 \mathrm{~mm})$ was greater than that of Experiment $2(0.42 \mathrm{~mm})$ and Experiment $3(0.32 \mathrm{~mm}$; see Table 1$)$. This is attributed to the different timing of the experiment runs with respect to tillage. Experiment 1 was performed in early August, soon after harvest, so the soil surface had recently been disturbed. However, for Experiments 2 and 3, which were performed in late September, the soil presented less surface disturbance due to the cumulative action of runoff from upslope areas on the plots arising from natural rainfall within that period (Papanicolaou et al., 2015b). Therefore, despite tamping with plywood, remnants of tillage effects remained in Experiment 1 , yielding different initial microroughness length scales to those in Experiments 2 and 3. This, however, is not an issue since all the results are presented herein in a dimensionless form (see Sect. 2.2 below on the index ratios). All cases, nonetheless, exhibited initial microroughness length of less than $2 \mathrm{~mm}$, corresponding to smooth surface bed conditions, as confirmed with the laser scanner. Dry soil bulk density was $1.25 \mathrm{~g} \mathrm{~cm}^{-3}$ for Experiment 1, and about $6 \%$ higher for Experiments 2 and 3 due to self-weight consolidation of soil.

Figure 5a provides an example of the experimental plot at prerainfall and postrainfall conditions. Since the focus of this research is only on plot regions where raindrop detachment is dominant over runoff, we are using the scanned profiles that correspond only to these upslope locations, which are shown in Fig. 5b. Rill formation was not observed in these regions throughout the experiments. Visual observations confirmed that raindrop detachment was dominant and the main driver of the change in soil surface roughness. For scanned profiles within the region of interest (ROI; i.e., a selected $200 \mathrm{~mm} \times 200 \mathrm{~mm}$ window size), we extracted the data for further statistical and geostatistical analyses by utilizing the public-domain R software (https://www.r-project.org/). The geostatistics ("gstat") and spatial analysis ("sp") libraries were imported to create sample semivariograms. 
Table 1. Summary of the rainfall-induced change in the RR index in the experimental tests of this study, as well as in experiments reported in the literature. Smooth conditions refer to initial microroughness less than $5 \mathrm{~mm}$. Cumulative rainfall amounts are also provided.

\begin{tabular}{|c|c|c|c|c|c|}
\hline $\begin{array}{l}\text { Rainfall } \\
\text { intensity } \\
\left(\mathrm{mm} \mathrm{h}^{-1}\right)\end{array}$ & $\begin{array}{r}\text { Cumulative } \\
\text { rainfall } \\
(\mathrm{mm})\end{array}$ & Soil type & $\begin{array}{c}\text { Prerainfall } \\
\text { RR (mm) }\end{array}$ & $\begin{array}{c}\text { Postrainfall } \\
\text { RR (mm) }\end{array}$ & $\begin{array}{c}\mathrm{RR} \\
\text { ratio }\end{array}$ \\
\hline & & & \multicolumn{3}{|c|}{ Present study } \\
\hline 30 & 150 & silty clay loam & 1.17 & 1.57 & 1.34 \\
\hline 60 & 300 & silty clay loam & 0.42 & 1.48 & 3.55 \\
\hline \multirow[t]{2}{*}{75} & 375 & silty clay loam & 0.32 & 1.46 & 4.56 \\
\hline & & & \multicolumn{3}{|c|}{ Vázquez et al. (2008)* } \\
\hline 30 & 85 & silt loam & 3.39 & 3.70 & 1.09 \\
\hline 30 & 50 & silt loam & 3.00 & 2.13 & 0.71 \\
\hline \multirow[t]{2}{*}{65} & 195 & silt loam & 4.72 & 5.10 & 1.08 \\
\hline & & & \multicolumn{3}{|c|}{ Zheng et al. (2014) } \\
\hline 40 & $\sim 60$ & silty clay loam & 2.01 & 2.35 & 1.17 \\
\hline 90 & $\sim 135$ & silty clay loam & 2.40 & 2.68 & 1.12 \\
\hline
\end{tabular}

* The Vázquez et al. (2008) study looked at RR evolution under successive rainfall events, unlike the other two studies. Postrainfall RR data presented for Vázquez et al. (2008) are those that were determined on completion of the last rainfall succession in each experiment.

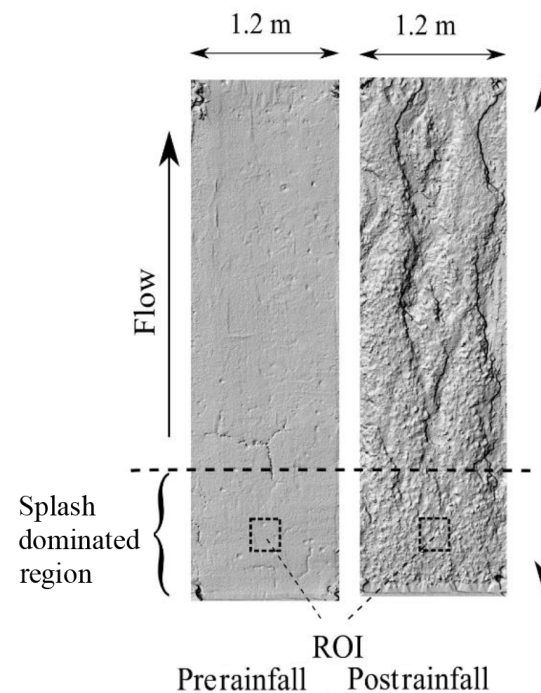

(a)

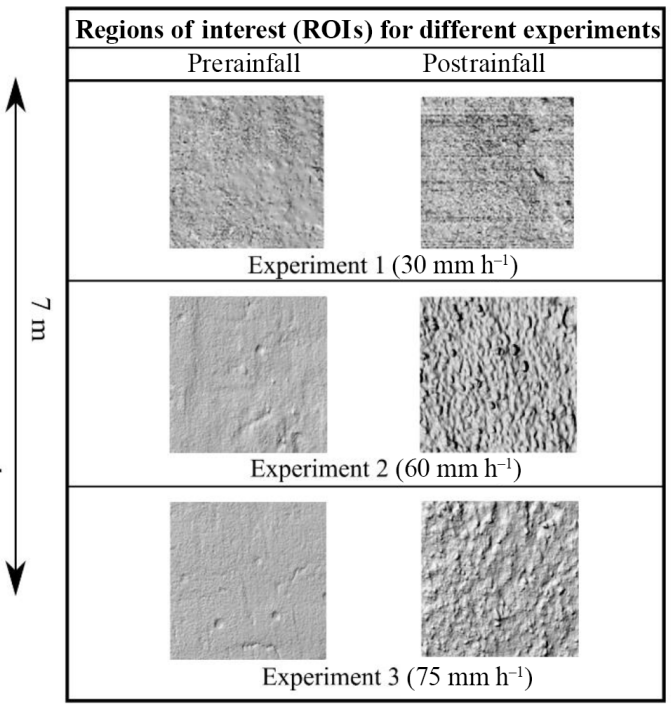

(b)

Figure 5. (a) Experimental plot under pre- and postrainfall conditions for an experimental test. The dashed boxes indicate the extent of the region of interest (ROI), where raindrop detachment is dominant over runoff. (b) Scanned profiles extracted from the laser-scanned areas of the three experimental tests considered, under both pre- and postrainfall conditions.

\subsection{Soil surface roughness quantification}

According to Paz-Ferreiro et al. (2008), the RR index, which was first proposed by Allmaras et al. (1966), is the most widely used statistical microrelief index for the evaluation of soil surface roughness. The RR index was initially calculated per Allmaras et al. (1966) as the standard deviation of the log-transformed residual point elevation data. In this study, it is calculated according to Currence and Lovely (1970) as the standard deviation of bed surface elevation data around the mean elevation, after correction for slope using the best-fit plane and removal of tillage effects in the individual height readings: 
$\mathrm{RR}=\sqrt{\frac{\sum_{i=1}^{n}\left(Z_{i}-\bar{Z}\right)^{2}}{n}}$,

where $Z_{i}$ and $\bar{Z}$ are individual elevation height readings and their mean, respectively, and $n$ is the total number of readings. The RR index calculated from Eq. (1) is the principal method to quantify soil surface roughness due to its frequent and widespread use in various studies and landscape models as a descriptor of microroughness. The RR index, however, requires that there is no spatial correlation between the surface elevations (Huang and Bradford, 1992). Hence, special care must be taken in adopting the RR index. If correlation exists within a certain spatial scale, the RR index will likely change with the changing window size of observed data (PazFerreiro et al., 2008) and may be dependent on the resolution of the measurement device (Huang and Bradford, 1992). Thus, alternative scale-independent methods that consider spatial correlation have been developed by other researchers in order to address this issue. These methods include firstorder variogram analysis (Linden and Van Doren, 1986; PazFerreiro et al., 2008), semivariogram analysis (Vázquez et al., 2005; Oleschko et al., 2008; Rosa et al., 2012; Vermang et al., 2013), fractal models based on fractional Brownian motion (Burrough, 1983; Vázquez et al., 2005; Papanicolaou et al., 2012; Vermang et al., 2013), multifractal analysis (Lovejoy and Schertzer, 2007; Vázquez et al., 2008), Markov-Gaussian models (Huang and Bradford, 1992; Vermang et al., 2013), and two-dimensional Fourier transform models (Cheng et al., 2012), among others. We herein employ additional indices derived from the first-order variogram and the semivariogram as alternatives to the RR index, which is also utilized accounting for its limitations. These include the crossover length, the Markov-Gaussian variance length scale, and the limiting difference.

The crossover length derived from semivariogram analysis is an index that is commonly used in most recent soil microrelief studies to describe surface microroughness. It has the advantage of its quantification being scale-independent through the consideration of the spatial correlation between surface elevations (Vidal Vázquez et al., 2007; Paz-Ferreiro et al., 2008; Tarquis et al., 2008). The semivariogram is calculated from the following equation:

$\gamma(h)=\frac{1}{2 n(h)} \sum_{i=1}^{n(h)}\left[Z\left(x_{i}+h\right)-Z\left(x_{i}\right)\right]^{2}$,

where $\gamma(h)$ is the semivariance, $h$ is the lag distance between data points, $Z(x)$ is the elevation height value at location $x$ after correction for both slope and tillage marks, and $n(h)$ is the total number of pairs separated by lag distance $h$ considered in the calculation. The semivariogram is the plot of the semivariance with respect to the lag distance.
Key indices for describing soil surface roughness can be derived from the semivariogram. Assuming a fractional Brownian motion model for describing soil surface roughness (as proposed in the pioneering work of Mandelbrot and Van Ness, 1968), the following expression for $\gamma(h)$ that incorporates the generalized Hurst exponent, $H$ is obtained (Huang and Bradford, 1992; Vidal Vázquez et al., 2007; PazFerreiro et al., 2008; Tarquis et al., 2008):

$\gamma(h)=l^{2-2 H} h^{2 H}$,

where $H$ is a measure of the degree of correlation between the surface elevations at lag distance $h$ with $0<H<1$, and $l$ is the crossover length. The crossover length is a measure of the vertical variability of soil surface roughness on the particular scale where the fractal dimension is estimated, and hence greater roughness is associated with larger crossover length values and vice versa (Huang and Bradford, 1992). The generalized Hurst exponent is a less sensitive descriptor of soil surface evolution as influenced by rainfall (Vázquez et al., 2005), and hence attention is mostly centered on the crossover length. Given the semivariogram plot calculated using Eq. (2), $H$ and $l$ can be extracted by fitting a power law relationship in the form of $y=A x^{B}$ to the semivariancelag distance data, where $y=\gamma(h)$ and $x=h$. According to Eq. (3), the $B$ regression variable gives the generalized Hurst exponent value and the $A$ regression variable yields the crossover length.

The Markov-Gaussian model is a random process that has been adopted for the quantification of soil surface roughness (Huang and Bradford, 1992; Vermang et al., 2013). In that case, the semivariogram is written as an exponential-type function with the following form:

$\gamma(h)=\sigma^{2}\left(1-e^{-h / L}\right)$,

where $\sigma$ is the variance length scale, representing the roughness of a surface on the large scale, and $L$ is the correlation length scale, which is a measure of the rate at which small-scale roughness variations approach the constant value of $\sigma$. These indices are obtained by fitting the exponentialtype function of Eq. (4) to the semivariogram obtained from Eq. (2).

Finally, the limiting difference (LD) index is another index adopted to quantify soil surface roughness. It is calculated from the first-order variogram with elevation data corrected for both slope and tillage marks (Linden and Van Doren, 1986; Paz-Ferreiro et al., 2008), which is written in the following form:

$\Delta Z(h)=\frac{1}{n(h)} \sum_{i=1}^{n(h)}\left|Z\left(x_{i}+h\right)-Z\left(x_{i}\right)\right|$.

Then, a linear relationship is fitted between $1 / \Delta Z(h)$ and $1 / h$ : 


$$
1 / \Delta Z(h)=a+b / h .
$$

The $\mathrm{LD}$ index is then calculated as $\mathrm{LD}=1 / a$. $\mathrm{LD}$ has units of length and represents the value of the first-order variance at large lag distances. It is considered to be an indicator of soil surface roughness, and is thus adopted in the present study as an additional roughness index.

In order to negate the effects of the differences that existed in the initial microrelief amongst the three runs due to the different timing of the experiments (see Sect. 2.1) and to compare rainfall-induced changes in relative terms, the results from the rainfall experiments are presented in the form of ratios of the roughness indices. More precisely, the RR ratio, defined as the ratio of the postrainfall $R R$ index over the $R R$ index prior to the rainfall $\left(R_{\text {post }} / R_{\text {pre }}\right)$, is calculated for each experiment. Semivariograms are plotted under preand postrainfall conditions at the ROI to assess the spatial correlation of surface elevations. Along the same lines, ratios between pre- and postrainfall conditions are calculated for the crossover length, the variance length scale of the Markov-Gaussian model, and the limiting difference to assess changes in microroughness along with the RR ratio.

\section{Results}

\subsection{Changes in the RR index}

Based on visual inspection of the DEMs in Fig. 5b, it is evident that microroughness in the splash-dominated region increases with rainfall. Table 1 summarizes the results of this study along with results from other studies focused on smooth surfaces, documenting the RR index values before and after the rainfall events, the cumulative rainfall, and the associated RR ratio. The present study, along with Vázquez et al. (2008) and Zheng et al. (2014) generally report an increase in RR with rainfall under the conditions examined. The Vázquez et al. (2008) study, however, differs from the present study and that of Zheng et al. (2014) in that it examined roughness evolution under successive rainfall events per run. Only the RR data collected on completion of the last rainfall succession in each run conducted by Vázquez et al. (2008) are presented in Table 1. The final RR values after the last rainfall succession were selected for being the more closely comparable to the steady-state conditions examined herein. Although both Vázquez et al. (2008) and Zheng et al. (2014) recorded an increase in RR with rainfall, they had significantly lower values of the RR ratio than the present study. This could be due to several factors including, but not limited to, lower applied rainfall intensity and amount, the initial surface microroughness, and different soil conditions.

Other studies not included in Table 1 have also shown increasing trends of roughness with rainfall, as quantified with the use of different indices. For instance, Huang and Bradford (1992) calculated the semivariograms for different sur- faces and used fractal and Markov-Gaussian parameters to quantify the roughness. Markov-Gaussian analysis showed a relative increase in the roughness parameter for a surface of low initial roughness. Finally, Rosa et al. (2012) introduced the roughness index, which is estimated from the semivariogram sill (i.e., the upper value where the semi-variance levels out), in order to quantify roughness, and observed an increase with rainfall under low initial roughness conditions. That increase was attributed to the fragmentation of aggregates and clods to smaller aggregates but was not linked to smooth bare soil surface conditions. Overall, the experimental evidence suggests that the interaction between rainfall and smooth soil surfaces can lead to an increase in microroughness.

The results outlined above for the use of the RR index as a descriptor of change in microroughness have been based on the assumption that there is no statistically significant spatial correlation in elevation readings between neighboring locations at the ROI. This condition was indeed not violated due to the choice in ROI. The following subsection outlines and discusses the results of the semivariogram analysis and additional indices used to confirm the validity of the assumption and their comparison with the RR index method.

\subsection{Changes in alternative roughness indices}

Semivariograms and first-order variograms were obtained from geostatistical analysis and plotted at four different angles $-0,45,90$, and $135^{\circ}$ - with respect to the downslope direction. Since the action of rainfall is isotropic and adds no systematic trend along any direction, no significant differences were expected between semivariograms. A nonparametric test for spatial isotropy was performed per Guan et al. (2004) using the public domain R statistical package with the "spTest" library. The spatial isotropy hypothesis was confirmed $(p<0.05)$. Thus, no bias was determined in taking any direction to calculate the semivariograms and the associated crossover lengths.

The semivariograms calculated at the ROI were chosen to be in the downslope direction at an angle of $0^{\circ}$ and are presented for each experiment in Fig. 6. The vertical dashed lines designate the lag distances above which the spatial autocorrelation of the elevations is not statistically significant. These lag distances are approximately $10 \mathrm{~mm}$, so the selected $200 \mathrm{~mm}$ window size of the ROI is almost 20 times greater than the spatial autocorrelation range. This implies that the window size of the ROI falls on the scale of the semivariogram sill (which is defined as the near-constant value of semivariance at large lag distances where the semivariogram levels out - see horizontal dashed lines in Fig. 6). RR is directly related to the semivariogram sill (e.g., Vázquez et al., 2005; Vermang et al., 2013); therefore it can be considered independent of the selected window size, given that the latter far exceeds the spatial autocorrelation range. 

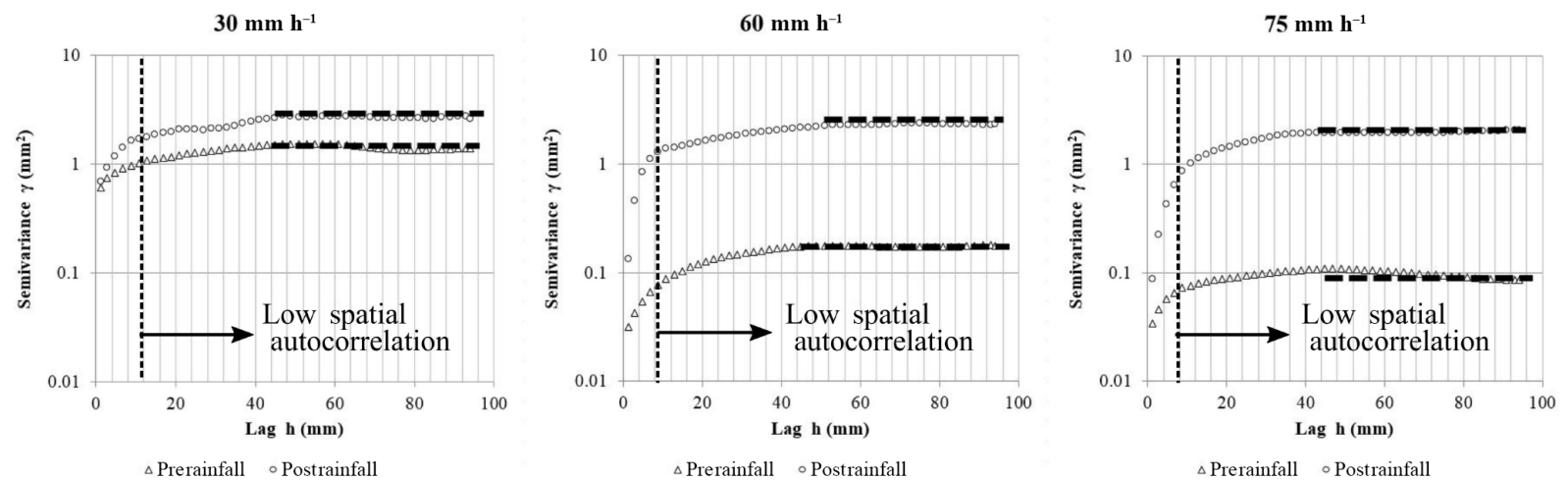

Figure 6. Semivariograms at the region of interest for the three experimental tests, under pre- and postrainfall conditions. Horizontal dashed lines indicate the semivariogram sills and vertical dashed lines indicate the lag distance above which the spatial autocorrelation of the elevations is negligible.

Figure 6 shows that the postrainfall sills are greater than their corresponding prerainfall values. Also, the difference in sills between pre- and postrainfall conditions for the $30 \mathrm{~mm} \mathrm{~h}^{-1}$ precipitation intensity is much lower than those of the 60 and $75 \mathrm{~mm} \mathrm{~h}^{-1}$ events. These observations are in accordance with visual inspection of the surfaces as well as with the results noted earlier for the RR ratio (see Table 1). Complete agreement between the trends of the RR index, the semivariogram sill, and visual inspection of the surfaces justifies the use of the RR index as a representative and unbiased descriptor of microroughness.

Table 2 lists the crossover length, the Markov-Gaussian variance length scale and the limiting difference indices for the three experimental tests, and their relative change after the rainfall. These indices show an increase with rainfall that is of the same magnitude and trend as the RR index and crossover length and provide a supplemental analysis about the role of rainfall intensities on the relative increase in roughness. Our findings were compared against those reported in the literature. Huang and Bradford (1992) studied the evolution of soil surface roughness with the MarkovGaussian variance length scale, and saw an increase of $6 \%$ in roughness for a surface of low initial roughness. Moreover, Paz-Ferreiro et al. (2008), who used the LD index to quantify soil surface roughness, also recorded a $10 \%$ increase in the LD index for a low roughness conventional tillage soil surface. The higher relative increase in roughness seen in our study (Table 2) compared to other studies is attributed to the lower initial roughness conditions in addition to different soil types and management.

Overall, the results provided suggest that all the indices employed in this study may be used interchangeably to characterize rainfall-induced changes in soil surface roughness and can capture an increase in soil surface roughness, especially for smooth soil surfaces. For these microroughness scales, the relative increase in roughness is also shown to in-
Table 2. Summary of the rainfall-induced change in the crossover length, the Markov-Gaussian variance length scale and limiting difference indices for the experimental tests of this study.

\begin{tabular}{lcccc}
\hline $\begin{array}{l}\text { Rainfall } \\
\text { intensity } \\
\left(\mathrm{mm} \mathrm{h}^{-1}\right)\end{array}$ & $\begin{array}{c}\text { Cumulative } \\
\text { rainfall } \\
(\mathrm{mm})\end{array}$ & $\begin{array}{c}\text { Pre- } \\
\text { rainfall } \\
\text { value }\end{array}$ & $\begin{array}{c}\text { Post- } \\
\text { rainfall } \\
\text { value }\end{array}$ & $\begin{array}{c}\text { Index } \\
\text { ratio }\end{array}$ \\
\hline & & \multicolumn{3}{c}{$l(\mathrm{~mm})$} \\
\cline { 3 - 5 } 30 & 150 & 0.71 & 0.73 & 1.03 \\
60 & 300 & 0.09 & 0.20 & 2.13 \\
75 & 375 & 0.15 & 0.39 & 2.56 \\
\hline & & & $\sigma(\mathrm{mm})$ \\
\cline { 3 - 5 } 30 & 150 & 1.19 & 1.63 & 1.37 \\
60 & 300 & 0.42 & 1.52 & 3.62 \\
75 & 375 & 0.31 & 1.43 & 4.56 \\
\hline & & & $\mathrm{LD}(\mathrm{mm})$ & \\
\cline { 3 - 5 } 30 & 150 & 0.79 & 0.87 & 1.10 \\
60 & 300 & 0.26 & 0.87 & 3.39 \\
75 & 375 & 0.15 & 0.71 & 4.84 \\
\hline
\end{tabular}

crease with rainfall intensity under the conditions examined herein.

\section{Discussion and conclusions}

Many studies have examined the response of rough surfaces to rainfall and have reported a decay of roughness. Few studies have assessed microscale variation of smooth surfaces in response to rainfall under controlled conditions. The experiments presented herein were designed to help us decipher the role of rain splash on RR for smooth surfaces with initial microroughness on the order of $2 \mathrm{~mm}$ by isolating the role of other factors such as runoff, variable water content, bare soil surface, and soil texture, among others. Our results show a 
consistent increase in roughness under the action of rainfall, with an overall agreement between all the roughness indices examined herein in terms of trend and magnitude. Our findings are consistent with findings of other studies that have examined length scales less than $5 \mathrm{~mm}$ and suggest the possible existence of a characteristic roughness threshold below which RR is expected to increase due to the action of rainfall. The value of this threshold may depend on the specific soil and rainfall conditions. A caveat of our study is that due to the limited range of conditions examined herein more experiments are needed to further solidify the conditions under which RR is expected to increase under rainfall action. An outcome of this study is the awareness that within landscape regions where smooth surfaces are present, an increase in RR may occur during the early part of the storm where rain splash action is more important than runoff.

This study suggests that the effects of the interaction between rainfall and a soil surface can be different for smooth and rough surfaces, and highlights the need for a better understanding of the interaction due to its potential impact on hydrologic response. This potential impact is demonstrated with the following established pedotransfer function for the effects of soil crusting, roughness, and rainfall kinetic energy on the bare hydraulic conductivity, $K_{\text {br }}$ (Risse et al., 1995):

$K_{\mathrm{br}}=K_{\mathrm{b}}\left[\mathrm{CF}+(1-\mathrm{CF}) e^{-C \cdot E_{a}\left(1-\mathrm{RR}_{t} / \mathrm{RR}_{t-\max }\right)}\right]$,

where $K_{\mathrm{b}}$ is the baseline hydraulic conductivity, $\mathrm{CF}$ is the crust factor, $C$ is the soil stability factor, $E_{a}$ is the cumulative rainfall kinetic energy since the last tillage, $R_{t}$ is random roughness height, and $\mathrm{RR}_{t-\max }$ is the maximum random roughness height. Using the following typical values for the study site based on the literature (Flanagan and Nearing, 1995; Chang, 2010), $E_{a}=10000 \mathrm{~J} \mathrm{~m}^{-2}, C=0.0002 \mathrm{~m}^{2} \mathrm{~J}^{-1}$, and $\mathrm{RR}_{t-\max }=40 \mathrm{~mm}$, the percentage change in bare hydraulic conductivity for increasing roughness can be estimated for an initial $\mathrm{RR}_{t}$ value of $2 \mathrm{~mm}$ and minimal CF factor. Performing the analysis for the range of random roughness ratios observed in this study $(\sim 1.3-4.5)$, the percentage increase in hydraulic conductivity is found to range between 5 and $42 \%$, which will have a significant impact on rainfallrunoff partitioning.

It is recognized that the soil preparation method in our study could have introduced some bias to the soil properties such as aggregate size distribution, compaction, and aggregate stability. Nonetheless, with regard to the purpose for which this study was designed, this preparation method ensured consistency in the initial and final roughness states, as confirmed by replications of our experimental runs. It is also recognized that drier, silty-type soils may not exhibit the increase in RR shown here. Further, the role of sealing may be important on roughness development under bare soil conditions and needs further examination. Soil water retention characteristics of the soils under sealing and its implication to RR must be considered (Saxton and Rawls, 2006). Finally, the role of successive storm events on changing roughness for smooth surfaces is not covered in this study and needs to be examined.

The exact mechanisms leading to increase in roughness remain unknown and are not the focus of this study. However, changes in roughness during a storm event have been attributed to compression and drag forces from the raindrop impact on the soil, angular displacement due to rain splash, aggregate fragmentation, and differential swelling (Al-Durrah and Bradford, 1982; Warrington et al., 2009; Rosa et al., 2012; Fu et al., 2016). Regions exhibiting different median raindrop diameters may experience different soil surface roughness evolution due to different aggregate fragmentation and rain splash effects (Warrington et al., 2009; Rosa et al., 2012; Fu et al., 2016). Future research should explore these mechanisms.

Data availability. The data of this research are available to the interested reader upon written request to any of the first three authors.

Competing interests. The authors declare that they have no conflict of interest.

Acknowledgements. The present study was in part supported by the National Science Foundation grant EAR1331906 for the Critical Zone Observatory for intensively managed landscapes (IML$\mathrm{CZO}$ ), which comprises a multi-institutional collaborative effort. The authors, especially the corresponding author, would like to acknowledge the help provided by Chi-Hua Huang from the USDA-ARS National Soil Erosion Research Lab, West Lafayette, IN, regarding the purchase of the laser system used in this research to map the RR. The fifth author was partially supported by the University of Iowa NSF IGERT program, Geoinformatics for Environmental and Energy Modeling and Prediction. This research was supported by the NASA EPSCoR Program (grant no. NNX10AN28A) and the Iowa Space Grant Consortium (grant no. NNX10AK63H). The first author during part of this analysis has been supported by the USDA-AFRI grant. Finally, we would like to thank the anonymous reviewers, whose insightful comments and suggestions led to an improved paper.

Edited by: Daniel Schertzer

Reviewed by: three anonymous referees 


\section{References}

Abaci, O. and Papanicolaou, A. N.: Long-term effects of management practices on water-driven soil erosion in an intense agricultural sub-watershed: monitoring and modelling, Hydrol. Process., 23, 2818-2837, https://doi.org/10.1002/hyp.7380, 2009.

Al-Durrah, M. M. and Bradford, J. M.: The mechanism of raindrop splash on soil surfaces, Soil Sci. Soc. Am. J., 46, 1086, https://doi.org/10.2136/sssaj1982.03615995004600050040x, 1982.

Allmaras, R. R., Burwell, R. E., Larson, W. E., and Holt, R. F.: Total porosity and random roughness of the interrow zone as influenced by tillage, USDA Conservation Re. Rep. 7, USDA, Washington, D.C., 16 pp., 1966.

Bertuzzi, P., Rauws, G., and Courault, D.: Testing roughness indices to estimate soil surface roughness changes due to simulated rainfall, Soil Till. Res., 17, 87-99, https://doi.org/10.1016/01671987(90)90008-2, 1990.

Burrough, P. A.: Multiscale sources of spatial variation in soil. I. The application of fractal concepts to nested levels of soil variation, J. Soil Sci., 34, 577-597, https://doi.org/10.1111/j.13652389.1983.tb01057.x, 1983.

Chang, Y.: Predictions of saturated hydraulic conductivity dynamics in a midwestern agriculture watershed, Iowa, MS Thesis, The University of Iowa, Iowa City, IA, USA, 2010.

Cheng, Q., Sun, Y., Lin, J., Damerow, L., Schulze Lammers, P., and Hueging, H.: Applying two-dimensional Fourier Transform to investigate soil surface porosity by laser-scanned data, Soil Till. Res., 124, 183-189, https://doi.org/10.1016/j.still.2012.06.016, 2012.

Chi, Y., Yang, J., Bogart, D., and Chu, X.: Fractal Analysis of Surface Microtopography and its Application in Understanding Hydrologic Processes, T. ASABE, 55, 1781-1792, https://doi.org/10.13031/2013.42370, 2012.

Currence, H. D. and Lovely, W. G.: The analysis of soil surface roughness, T. ASAE, 13, 710-714, 1970.

Darboux, F. and Huang, C.: An instantaneous-profile laser scanner to measure soil surface microtopography, Soil Sci. Soc. Am. J., 67, 92-99, https://doi.org/10.2136/sssaj2003.9200, 2003.

Elhakeem, M. and Papanicolaou, A. N.: Estimation of the runoff curve number via direct rainfall simulator measurements in the State of Iowa, USA, Water Resour. Manage., 23, 2455-2473, https://doi.org/10.1007/s11269-008-9390-1, 2009.

Flanagan, D. C. and Nearing, M. A. (Eds.): USDA Water Erosion Prediction Project: Hillslope Profile and Watershed Model Documentation, NSERL Report No. 10, USDA-ARS National Soil Erosion Research Laboratory, West Lafayette, IN, USA, 1995.

Fu, Y., Li, G., Zheng, T., Li, B., and Zhang, T.: Impact of raindrop characteristics on the selective detachment and transport of aggregate fragments in the Loess Plateau of China, Soil Sci. Soc. Am. J., 80, 1071, https://doi.org/10.2136/sssaj2016.03.0084, 2016.

Gilley, J. E. and Finkner, S. C.: Hydraulic roughness coefficients as affected by random roughness, T. ASAE, 34, 897-903, https://doi.org/10.13031/2013.31746, 1991.

Gómez, J. A. and Nearing, M. A.: Runoff and sediment losses from rough and smooth soil surfaces in a laboratory experiment, Catena, 59, 253-266, https://doi.org/10.1016/j.catena.2004.09.008, 2005.
Guan, Y., Sherman, M., and Calvin, J. A.: A nonparametric test for spatial isotropy using subsampling, J. Am. Stat. Assoc., 99, 810821, https://doi.org/10.1198/016214504000001150, 2004.

Huang, C. and Bradford, J. M.: Depressional storage for Markov-Gaussian surfaces, Water Resour. Res., 26, 2235-2242, https://doi.org/10.1029/WR026i009p02235, 1990.

Huang, C. and Bradford, J. M.: Applications of a laser scanner to quantify soil microtopography, Soil Sci. Soc. Am. J., 56, 1421, https://doi.org/10.2136/sssaj1992.03615995005600010002x, 1992.

Huff, F. A. and Angel, J. R.: Rainfall Frequency Atlas of the Midwest, Midwestern Climate Center Research Report 92-03, Midwestern Climate Center Research, Champaign, IL, 1992.

Kamphorst, E. C., Jetten, V., Guérif, J., Pitkanen, J., Iversen, B. V., Douglas, J. T., and Paz, A.: Predicting depressional storage from soil surface roughness, Soil Sci. Soc. Am. J., 64, 1749, https://doi.org/10.2136/sssaj2000.6451749x, 2000.

Linden, D. R. and Van Doren, D. M.: Parameters for characterizing tillage-induced soil surface roughness, Soil Sci. Soc. Am. J., 50, 1560, https://doi.org/10.2136/sssaj1986.03615995005000060035x, 1986.

Lovejoy, S. and Schertzer, D.: Scaling and multifractal fields in the solid earth and topography, Nonlin. Processes Geophys., 14, 465-502, https://doi.org/10.5194/npg-14-465-2007, 2007.

Magunda, M. K., Larson, W. E., Linden, D. R., and Nater, E. A.: Changes in microrelief and their effects on infiltration and erosion during simulated rainfall, Soil Technol., 10, 57-67, https://doi.org/10.1016/0933-3630(95)00039-9, 1997.

Mandelbrot, B. B. and Van Ness, J. W.: Fractional Brownian motions, fractional noises and applications, SIAM Review, 10, 422437, 1968.

Marshall, J. S. and Palmer, W. M. K.: The distribution of raindrops with size, J. Meteorol., $\quad 5, \quad 165-166, \quad$ https://doi.org/10.1175/15200469(1948)005<0165:TDORWS>2.0.CO;2, 1948.

Mohamoud, Y. M., Ewing, L. K., and Boast, C. W.: Small plot hydrology: I. Rainfall infiltration and depression storage determination, T. ASAE, 33, 1121-1131, https://doi.org/10.13031/2013.31448, 1990.

Oades, J. and Waters, A.: Aggregate hierarchy in soils, Aust. J. Soil Res., 29, 815-828, https://doi.org/10.1071/SR9910815, 1991.

Oleschko, K., Korvin, G., Muñoz, A., Velazquez, J., Miranda, M. E., Carreon, D., Flores, L., Martínez, M., Velásquez-Valle, M., Brambila, F., Parrot, J. F., and Ronquillo, G.: Mapping soil fractal dimension in agricultural fields with GPR, Nonlin. Processes Geophys., 15, 711-725, https://doi.org/10.5194/npg-15711-2008, 2008.

Papanicolaou, A. N., Tsakiris, A. G., and Strom, K.: The use of fractals to quantify the morphology of cluster microform, Geomorphology, 139-140, 91-108, https://doi.org/10.1016/j.geomorph.2011.10.007, 2012.

Papanicolaou, A. N., Elhakeem, M., Wilson, C. G., Burras, C. L., West, L. T., Lin, H., Clark, B., and Oneal, B. E.: Spatial variability of saturated hydraulic conductivity at the hillslope scale: Understanding the role of land management and erosional effect, Geoderma, 243-244, 58-68, https://doi.org/10.1016/j.geoderma.2014.12.010, 2015a. 
Papanicolaou, A. N., Wacha, K. M., Abban, B. K., Wilson, C. G., Hatfield, J. L., Stanier, C. O., and Filley, T. R.: From soilscapes to landscapes: A landscape-oriented approach to simulate soil organic carbon dynamics in intensively managed landscapes, J. Geophys. Res.-Biogeo., 120, 2375-2401, https://doi.org/10.1002/2015JG003078, 2015b.

Paz-Ferreiro, J., Bertol, I., and Vázquez, E. V.: Quantification of tillage, plant cover, and cumulative rainfall effects on soil surface microrelief by statistical, geostatistical and fractal indices, Nonlin. Processes Geophys., 15, 575-590, https://doi.org/10.5194/npg-15-575-2008, 2008.

Potter, K. N.: Soil properties effect on random roughness decay by rainfall, T. ASAE, 33, 1889-1892, 1990.

Risse, L. M., Liu, B. Y., and Nearing, M. A.: Using curve numbers to determine base-line values of Green-Ampt effective hydraulic conductivities, Water Resour. Bull., 31, 147-158, 1995.

Römkens, M. J. and Wang, J. Y.: Effect of tillage on surface roughness, T. ASAE, 29, 429-433, https://doi.org/10.13031/2013.30167, 1986.

Rosa, J. D., Cooper, M., Darboux, F., and Medeiros, J. C.: Soil roughness evolution in different tillage systems under simulated rainfall using a semivariogram-based index, Soil Till. Res., 124, 226-232, https://doi.org/10.1016/j.still.2012.06.001, 2012.

Saxton, K. E. and Rawls, W. J.: Soil water characteristic estimates by texture and organic matter for hydrologic solutions, Soil Sci. Soc. Am. J., 70, 1569, https://doi.org/10.2136/sssaj2005.0117, 2006.

Tarquis, A. M., Heck, R. J., Grau, J. B., Fabregat, J., Sanchez, M. E., and Antón, J. M.: Influence of thresholding in mass and entropy dimension of 3-D soil images, Nonlin. Processes Geophys., 15, 881-891, https://doi.org/10.5194/npg-15-881-2008, 2008.

Vázquez, E. V., Miranda, J. G. V., and González, A. P.: Characterizing anisotropy and heterogeneity of soil surface microtopography using fractal models, Ecol. Model., 182, 337-353, https://doi.org/10.1016/j.ecolmodel.2004.04.012, 2005.
Vázquez, E. V., Moreno, R. G., Miranda, J. G. V., Díaz, M. C., Requejo, A. S., Paz-Ferreiro, J., and Tarquis, A. M.: Assessing soil surface roughness decay during simulated rainfall by multifractal analysis, Nonlin. Processes Geophys., 15, 457-468, https://doi.org/10.5194/npg-15-457-2008, 2008.

Vermang, J., Norton, L. D., Baetens, J. M., Huang, C., Cornelis, W. M., and Gabriels, D.: Quantification of soil surface roughness evolution under simulated rainfall, T. ASABE, 56, 505-514, https://doi.org/10.13031/2013.42670, 2013.

Vidal Vázquez, E., Miranda, J. G. V., and Paz González, A.: Describing soil surface microrelief by crossover length and fractal dimension, Nonlin. Processes Geophys., 14, 223-235, https://doi.org/10.5194/npg-14-223-2007, 2007.

Wainwright, J., Parsons, A. J., and Abrahams. A. D.: Plotscale studies of vegetation, overland flow and erosion interactions: case studies from Arizona and New Mexico, Hydrol. Process., 14, 2921-2943, https://doi.org/10.1002/10991085(200011/12)14:16/17<2921::AID-HYP127>3.0.CO;2-7, 2000.

Warrington, D. N., Mamedov, A. I., Bhardwaj, A. K., and Levy, G. J.: Primary particle size distribution of eroded material affected by degree of aggregate slaking and seal development, Eur. J. Soil Sci., 60, 84-93, https://doi.org/10.1111/j.13652389.2008.01090.x, 2009.

Zhang, X., Yu, G. Q., Li, Z. B., and Li, P.: Experimental study on slope runoff, erosion and sediment under different vegetation types, Water Resour. Manage., 28, 2415-2433, 2014.

Zheng, Z. C., He, S. Q., and Wu, F.: Changes of soil surface roughness under water erosion process: Soil surface roughness under water erosion, Hydrol. Process., 28, 3919-3929, https://doi.org/10.1002/hyp.9939, 2014.

Zobeck, T. M. and Onstad, C. A.: Tillage and rainfall effects on random roughness: A review, Soil Till. Res., 9, 1-20, https://doi.org/10.1016/0167-1987(87)90047-X, 1987. 